\title{
O corpo como palco da subjetividade frente às vivências de sofrimento do trabalho: uma revisão bibliográfica na região amazônica
}

\author{
The body as a stage for subjectivity in the face of suffering at work: a bibliographical review in the
} Amazon region

El cuerpo como scenario de la subjetividad ante el sufrimiento en el trabajo: una revision bibliográfica en la region amazónica

Paulo de Tarso Ribeiro de Oliveira ORCID: https://orcid.org/0000-0002-1969-380X Universidade Federal do Pará, Brasil E-mail:pttarso@gmail.com

Maria Clara Acacio de Oliveira Brasil ORCID: https://orcid.org/0000-0003-4783-1330 Universidade Federal do Pará, Brasil E-mail: psic.claraoliveira@gmail.com

Anaclan Pereira Lopes da Silva ORCID: https://orcid.org/0000-0003-3469-5309 Universidade Federal do Pará, Brasil E-mail: anaclanlopes@gmail.com

Michele Torres dos Santos de Melo ORCID: https://orcid.org/0000-0002-9553-2960 Universidade Federal do Pará, Brasil E-mail: mts_psi@yahoo.com.br

\begin{abstract}
Resumo
O trabalho movimento a vida dos indivíduos e o ritmo em que o mundo ao seu redor irá correr. Na perspectiva da Psicodinâmica do Trabalho, teoria escolhida para nortear esse escrito, o trabalho possui papel central e organizador na vida dos sujeitos que viverão as experiencias trabalhistas entre o prazer e o sofrimento, ambos presentes e naturais no ambiente de trabalho. Nessas vivencias antagônicas a subjetividade do trabalhador e da trabalhadora estará implicadas no exercício de suas atividades, o corpo será o palco das experiencias e expressões dessa subjetividade frente ao trabalho. Portanto, o objetivo dessa pesquisa foi realizar uma análise do sofrimento impresso no corpo dos trabalhadores por meio da revisão de bibliográfica das publicações com aporte em Psicodinâmica do Trabalho de três programas de pesquisa da região amazônica. A análise dos fatores e processos de sofrimento refletidos no corpo demonstraram que os trabalhadores das publicações analisadas sofrem com a sobrecarga em seus respectivos trabalhos, além disso foi recorrente a ocorrência de acidentes e adoecimentos em razão de condições de trabalho repletas de riscos a saúde. Em face ao adoecimento os trabalhadores e trabalhadoras sofrem pelo afastamento do exercício laboral e abalo em sua identidade.
\end{abstract}

Palavras-chave: Saúde do trabalhador; Psicodinâmica do trabalho; Amazônia.

\begin{abstract}
Work moves the lives of individuals and the pace at which the world around them will run. From the perspective of the Psychodynamics of Work, theory chosen to guide this writing, work has a central and organizing role in the lives of subjects who will live work experiences between pleasure and suffering, both present and natural in the work environment. In these antagonistic experiences, the subjectivity of the worker and the worker will be involved in the exercise of their activities, the body will be the stage for the experiences and expressions of this subjectivity in the face of work. Therefore, the objective of this research was to carry out an analysis of the suffering printed on the workers' bodies through a bibliographic review of publications with a contribution in Psychodynamics of Work from three research programs in the Amazon region. The analysis of the factors and processes of suffering reflected in the body showed that the workers in the analyzed publications suffer from overload in their respective work, in addition to the recurrent occurrence of accidents and illnesses due to working conditions fraught with health risks. In the face of illness, male and female workers suffer from withdrawal from work and their identity is shaken.
\end{abstract}

Keywords: Occupational health; Psychodynamics of work; Amazon. 


\begin{abstract}
Resumen
El trabajo mueve la vida de las personas y el ritmo al que se desarrollará el mundo que las rodea. Desde la perspectiva de la Psicodinámica del Trabajo, teoría elegida para orientar este escrito, el trabajo tiene un papel central y organizador en la vida de los sujetos que vivirán experiencias laborales entre el placer y el sufrimiento, tanto presentes como naturales en el ámbito laboral. En estas vivencias antagónicas, la subjetividad del trabajador y el trabajador se involucrarán en el ejercicio de sus actividades, el cuerpo será el escenario de las vivencias y expresiones de esta subjetividad frente al trabajo. Por tanto, el objetivo de esta investigación fue realizar un análisis del sufrimiento impreso en el cuerpo de los trabajadores a través de una revisión bibliográfica de publicaciones con un aporte en Psicodinámica del Trabajo de tres programas de investigación en la región amazónica. El análisis de los factores y procesos de sufrimiento reflejados en el cuerpo mostró que los trabajadores de las publicaciones analizadas sufren sobrecarga en su respectivo trabajo, además de la recurrencia de accidentes y enfermedades por condiciones laborales cargadas de riesgos para la salud. Ante la enfermedad, los trabajadores sufren el retiro del trabajo y su identidad se ve afectada
\end{abstract}

Palabras clave: Salud del trabajador; Psicodinámica del trabajo; Amazonas.

\title{
1. Introdução
}

O trabalho produz movimento. De forma mais abrangente move os meios de produção, movimenta a política, faz com que o tempo se mova de forma desenfreada ou lenta, em uma perspectiva mais pontual e subjetiva o trabalho trás movimento ao sujeito, aciona sua subjetividade, move suas relações diárias, lhe empurra para seu papel social, e de forma literal e crua move seu corpo.

Ao falar dos movimentos produzidos pelo trabalho, retomamos a Psicodinâmica do Trabalho como farol que trará o foco para o caráter dinâmico que o trabalho exerce no psiquismo, além de movimenta-lo frente a vida cotidiana o trabalho exerce uma produção dúbia no indivíduo, em que dor e prazer são gerados a partir do exercício de uma atividade. Indo além da psicopatologia do trabalho, a teoria iniciada por Christophe Dejours olha para o indivíduo como ativo e partícipe no modo como o trabalho se constrói. Contanto com esta perspectiva, o presente escrito se embasa teóricamente em autores como Christophe Dejours, Ana Magnólia Mendes e Selma Lancman, escritores de grande relevancia para a Psicodinâmica do Trabalho.

Inserido em um ambiente de trabalho com condições específicas e uma organização que demandará ação do profissional, cada trabalhador se implicará nesse trabalho de forma subjetiva, tomando-o como fonte sublimatória. Os estudos de Dejours tomam como base os conceitos e premissas da psicanálise, portanto põe o trabalho em posição de relevante ponto de sublimação, ao explicar a sublimação Freud (1908) aponta as escolhas sublimatórias como uma forma substitutiva dos desejos (pulsões) sexuais do psiquismo que não podem ser atendidos dentro da moral de nossa sociedade, isto é, impedido de acatar os desejos sexuais do inconsciente propriamente dito, o sujeito direciona sua energia pulsional para outros desejos como o exercício de uma atividade.

Dejours acrescenta ainda que "a sexualidade não pode ser pensada sem referência ao corpo: corpo como origem da sexualidade, por um lado, corpo como teatro da própria sexualidade [...]” (Dejours, 1986). Portanto, é neste palco corporal vasto, frágil e resistente que o trabalhador irá dedicar-se a sua atividade, também é nele que o sofrimento biológico e psíquico se fará concreto. Reiterando esta ideia, Dejours (2012) afirma que “o corpo é o lugar da experiencia subjetiva, a subjetividade por meio do corpo comparecerá a produção desse trabalho".

Tendo em conta o trabalho como uma experiência subjetiva e corporal presente na vida de todo indivíduo, recorrentemente vívida semanalmente, faz-se necessário expor a realidade e as características na prática de um trabalho. A concepção de trabalho na teoria psicodinâmica vai muito além do exercício de uma função assalariada, Dejours definiu trabalho como:

“[...] aquilo que implica, do ponto de vista humano, o fato de trabalhar: gestos, saber-fazer, um engajamento do corpo, a mobilização da inteligência, a capacidade de refletir, de interpretar e de reagir às situações; é o poder de sentir, de pensar e de inventar, etc. Em outros termos, para o clínico, o trabalho não é em primeira instância a relação salarial ou o 
emprego; é o «trabalhar», isto é, um certo modo de engajamento da personalidade para responder a uma tarefa delimitada por pressões (materiais e sociais)." (Dejours, 2004)

Portanto, o trabalho se constituirá por um universo de experiências onde a subjetivada do trabalhador estará implicada, as experiências de trabalho serão resultado direto da forma da organização e das condições trabalhistas que é inerente a cada realidade profissional. Dejours (2008) definiu a Organização do Trabalho como um sistema de obrigações de ordem técnica. Sendo assim, a organização do trabalho tratará das funções prescritas ao trabalhador, da divisão do trabalho na instituição e dos parâmetros a serem seguidos para a operação do trabalho. A organização do trabalho também definirá as relações hierárquicas dentro do ambiente, dividindo responsabilidades compostas de relações de poder e obediência entre os trabalhadores (Dejours, 1993).

As incumbências profissionais exigidas pela organização do trabalho serão permeadas por condições trabalhistas, estas abrangem todo cenário em que o trabalhador estará corporalmente exercendo sua atividade, isto é, reportam-se as condições físicas do ambiente, como temperatura, altitude, intensidade sonora, também as condições biológicas como exposição a microrganismos, a desgastes osteomusculares, assim como circunstâncias de higiene e segurança (Bueno \& Macêdo, 2012).

As vivências de prazer e sofrimento inerentes ao trabalho dentro da sua organização perpassam pela resposta subjetiva frente a realidade do trabalho. O exercício de uma atividade na realidade prática sempre escapa ao que foi exigido "no papel”, formando o 'real do trabalho'. Nessa perspectiva, a organização do trabalho está recheada de pormenores e imprevistos que o trabalhador irá resolver desviando-se do trabalhar planejado, Dejours (2008, p.132) abordou isto fazendo uma diferença entre tarefa e atividade, enquanto que tarefa se refere ao que deveria ser feito de acordo com o que foi expressamente exigido ao trabalhador, a atividade é o que ele realmente fará reajustando as ações previamente estipuladas para que consiga alcançar os objetivos impostos. O trabalhado do modo que realmente é praticado o qual Dejours se referiu como Trabalho Vivo retomando o termo de Karl Marx (Dejours, 2012).

Portanto, é imprescindível entender que a rotina do trabalhdor é repleta de imprevistos (interpessoais, relacionais, ergonômicos e funcionais), tal composição cotidiana implica em uma rotineira necessidade de modificações e ajustes para que o trabalhador se preserve. Tais circunstâncias inadvertidas encontradas pelo trabalhador no seu dia-a-dia podem suceder angústia ao trabalhador, que evocará formas de defender-se dos sofrimentos. Esta autopreservação presente na prática do trabalho vivo é impressa por cada pessoa em razão de suas defesas psíquicas, o sentido do comportamento de um trabalhador parte do seu sofrimento como forma inteligível que este indivíduo encontra para evitar a aflição causada pelas exigências trabalhistas (Lancman, 2003).

Isto posto, o trabalhador mobiliza-se como um todo, transformando o trabalho em sua produção pessoal, na qual ele esforça-se para imputar qualidade, entregando toda seu potencial de criação e inteligência, ao ponto de dedicar o próprio corpo, onde se dá sua experiencia subjetiva, à excussão de sua atividade.(Dejours, 2012).

A produção das facetas de prazer e sofrimento trazidas pelo trabalho, serão vivencias psiquicamente e corporalmente de forma simultânea e interligada. O exercício de uma atividade trará ao corpo a satisfação da produção pessoal de um trabalhar, mas também trará as consequências desagradáveis em razão do esforço implicado pela estrutura física humana. Para além das consequências mecânicas e ergonômicas o corpo também será marcado pelas experiencias psíquicas, o que foi lavrado no psiquismo será inscrito no corporal, portanto, para além das consequências de caráter físico o corpo carregará os resultados dos processos psíquicos vividos no trabalho por meio da somatização.

McDougall (1989) considera como fenômenos psicossomáticos "tudo aquilo que atinge a saúde ou a integridade física quando os fatores psicológicos desempenham algum papel” (Mcdougall, 1989). A autora explana a respeito dos sintomas 
somáticos como uma resposta a um cenário psíquico angustiante mal resolvido, onde o surgimento do sintoma está atrelado a resposta a uma frustração inconsciente.

Reiterando o trabalho como atividade sublimatória, qualquer descompensação vinda desta atividade toca na sexualidade do indivíduo, nos seus conteúdos psíquicos, sendo passível o aparecimento de sintomas somáticos.

Levando em conta a posição imprescindível do corpo nas vivências de trabalho, este escrito tem como objetivo analisar os processos e fatores de sofrimento do corpo frente a realidade de trabalho, entendendo como este sustenta as cargas psíquicas e físicas provenientes da organização e das condições de trabalho.

\section{Metodologia}

A pesquisa realizada possui caráter qualitativo e é descritiva quantos aos seus objetivos, buscando analisar os processos de sofrimento do corpo frente a realidade do trabalho a partir da análise de publicações de 2008 à 2020 com aporte em Psicodinâmica do Trabalho feito nos seguintes programas da Universidade Federal do Pará: Programa de Pós-Graduação em Psicologia (PPGP), Programa de Pós-Graduação em Desenvolvimento do Trópico Úmido (PPGDSTU) e Programa de PósGraduação em Serviço Social (PPGSS). A pesquisa qualitativa oferece a pessoa que escreve o papel de interprete que produz um documento interpretativo afim de comunicar o que foi absorvido no estudo e no ato de pesquisar (Dezin \& Lincoln, 2006), logo, o presente escrito procura informar o que foi apreendido dos trabalhos analisados afim de responder aos objetivos propostos de por meio da interpretação cientifica.

Este trabalho se embasou na Psicodinâmica do Trabalho como teoria norteadora de discussões a respeito do mundo do trabalho. A psicodinâmica do trabalho é teoria e clínica, agregando todo conhecimento vindo de ambas as faces em um único campo do saber, entretanto utilizaremos nesse estudo o que Merlo e Mendes (2009) elucidaram como 'categoria teórica', isto é, faremos uso dos conceitos da psicodinâmica, das suas discussões teóricas e das suas perspectivas de análise, mas não a utilizaremos como método referente a pratica clinica feita a partir dela.

A escolha do referencial teórico foi feita a partir da seleção de autores de grande importância na área da psicodinâmica do trabalho e da psicanálise como teoria de suporte.

A escolha dos programas leva em conta sua relevância para pesquisa científica feita na região amazônica. As publicações foram geradas por pesquisas realizadas no PPGP, PPGDSTU e PPGSS por professores, doutorandos e mestrandos do programa. O critério de inclusão para o recorte de publicações a serem analisadas foi incluir teses, dissertações e artigos retirados dos programas citados, no período de doze anos (2008 a 2020) e que tivessem aporte teórico em Psicodinâmica do Trabalho. Portanto, a seleção das pesquisas utilizada para o alcance da proposta desse escrito culminou no seguinte quadro que expõe as publicações selecionadas, citando o ano de cada publicação, seus respectivos autores e os tipos de trabalho aos quais os estudos se referem: 
Quadro 1. Publicações análisadas no presente escrito.

\begin{tabular}{|c|c|c|c|}
\hline Ano & Autor & Título & Cargos/Funções entrevistadas \\
\hline 2008 & Rosangela Moraes & $\begin{array}{l}\text { Prazer-Sofrimento e saúde do trabalhador } \\
\text { com automação: estudo om operadores em } \\
\text { empresas japonesas no industrial de } \\
\text { Manaus. }\end{array}$ & Operador de máquina de inserção automática. \\
\hline 2011 & Andréa Mendes & $\begin{array}{l}\text { Saúde mental e trabalho na assistência } \\
\text { social: vivencias de sofrimento psíquico e } \\
\text { estratégias de defesa dos(as) servidores(as) } \\
\text { públicos(as) municipais da FUNPAPA em } \\
\text { Belém/PA. }\end{array}$ & $\begin{array}{l}\text { Assistente social, gestora, terapeuta } \\
\text { ocupacional, técnica em desporto e lazer, } \\
\text { educadora de arte, educador social, agente de } \\
\text { copa e cozinha, agente de serviços gerais e } \\
\text { agente de vigilância. }\end{array}$ \\
\hline 2011 & Josie Vieira & $\begin{array}{l}\text { Cuidar adoecendo: o que fazer quando não } \\
\text { posso mais usar todo meu potencial de } \\
\text { cuidar. }\end{array}$ & Enfermeiros e técnicos em enfermagem. \\
\hline 2011 & Laura Nogueira & $\begin{array}{l}\text { O Sofrimento Negado: trabalho, } \\
\text { saúde/doença dos trabalhadores do } \\
\text { alumínio do PARÁ-BR. }\end{array}$ & $\begin{array}{l}\text { Operador de forno, operador de equipamentos } \\
\text { auxiliares, eletricista, mecânico, motorista, } \\
\text { carpinteiro, técnico de segurança no trabalho, } \\
\text { gerente operacional, gerente de área e analista } \\
\text { de recursos humanos. }\end{array}$ \\
\hline 2013 & Eric Alvarenga & $\begin{array}{l}\text { A coragem de ser músico de Orquestra } \\
\text { Sinfônica: uma análise baseada na } \\
\text { Psicodinâmica do Trabalho. }\end{array}$ & $\begin{array}{l}\text { Músicos de Orquestra Sinfônica de diversos } \\
\text { instrumentos. }\end{array}$ \\
\hline 2013 & Marcia Abreu & $\begin{array}{l}\text { Subjetividade, trabalho e saúde dos } \\
\text { servidores do hospital universitário João de } \\
\text { Barros Barreto: prazer e sofrimento na } \\
\text { aposentadoria. }\end{array}$ & Técnicas e Auxiliares em enfermagem. \\
\hline 2014 & Renata Louzada & $\begin{array}{l}\text { Eu tenho medo é dos vivos: análise } \\
\text { psicodinâmica do trabalho entre } \\
\text { profissionais de medicina legal. }\end{array}$ & $\begin{array}{l}\text { Médico Legista, perito da odontologia legal, } \\
\text { auxiliar técnico em perícia, assistente } \\
\text { administrativo e auxiliar de limpeza. }\end{array}$ \\
\hline 2015 & Cristiane Silva & $\begin{array}{l}\text { Saúde, prazer e sofrimento psíquico: uma } \\
\text { análise do trabalho de técnicos em um } \\
\text { centro de referência de assistência social do } \\
\text { Pará. }\end{array}$ & $\begin{array}{l}\text { Gestora, Assistente } \text { Social, } \\
\text { educador Social, agente de copa e cozinha, } \\
\text { prestador de serviços gerais e auxiliar } \\
\text { administrativo. }\end{array}$ \\
\hline 2017 & $\begin{array}{l}\text { José Brito, Paulo } \\
\text { Kleber Oliveira, Paulo } \\
\text { Oliveira e Adelma } \\
\text { Pimentel }\end{array}$ & $\begin{array}{l}\text { A clínica do trabalho e o desvelamento do } \\
\text { traumático no trabalho de bombeiros } \\
\text { militares: fragmentos de um caso clínico. }\end{array}$ & Bombeiro militar. \\
\hline 2018 & Ana Mèlou & $\begin{array}{l}\text { Eu acho graça pra não chorar: uma análise } \\
\text { de psicodinâmica do trabalho de operadores } \\
\text { de caixa de supermercado. }\end{array}$ & Operadoras de caixa de supermercado. \\
\hline 2018 & Eric Alvarenga & $\begin{array}{l}\text { A corda bamba do trabalhar das equipes de } \\
\text { saúde da família em Belém. }\end{array}$ & $\begin{array}{l}\text { Enfermeira, médico, técnico em enfermagem, } \\
\text { agente administrativo, agente de portaria, } \\
\text { agente comunitário de saúde, auxiliar de } \\
\text { serviços gerais, auxiliar de saúde bucal e } \\
\text { piloto de lancha. }\end{array}$ \\
\hline 2020 & Daiane Calazans & $\begin{array}{l}\text { É preciso amar para trabalhar: saúde mental } \\
\text { dos trabalhadores de um CAPS II no estado } \\
\text { do Pará. }\end{array}$ & $\begin{array}{l}\text { Psicólogo, terapeuta ocupacional, enfermeira e } \\
\text { assistente social. }\end{array}$ \\
\hline 2020 & Mário Brito & $\begin{array}{l}\text { "Até onde o corpo aguenta somos humanos, } \\
\text { depois disso somos bombeiros": análise dos } \\
\text { riscos psicossociais relacionados à } \\
\text { organização e às condições de trabalho } \\
\text { bombeiro militar. }\end{array}$ & Bombeiro militar. \\
\hline
\end{tabular}

Fonte: https://ppgp.propesp.ufpa.br/index.php/br/

A escolha do Programa de Pós-Graduação em Psicologia (PPGP), do Programa de Pós-Graduação em Desenvolvimento Sustentável do Trópico Úmido (PPGDSTU) e do Programa de Pós-Graduação em Serviço Social leva em conta sua inexorável importância para pesquisa científica feita na região amazônica. Quando se trata de pesquisa em Psicodinâmica do Trabalho na 
região amazônica o professor Paulo de Tarso Ribeiro de Oliveira, pesquisador do PPGP, foi pioneiro com sua dissertação "O sofrimento psíquico e o trabalho hospitalar: um estudo de caso realizado em um hospital público no Pará" publicado em 1988 (Monteiro, Moraes, Freitas, Guizoni e Facas, 2019).

Os estudos do PPGP, PPGDSTU e PPGSS reunidos nesta pesquisa dispõem de temas focados em diversas categorias de trabalho. Sendo assim, foi encontrada na configuração desses trabalhos uma variedade de posições socioeconômica, de condições hierárquicas institucionais, assim como diferentes posições nos níveis da cadeia de produção e de área de conhecimento. As realidades de diferentes tipos de profissões reunidos nos estudos analisados permitiram uma visão mais ampla dos pesares do corpo no mundo do trabalho, pontuando como este está colocado nas diversas áreas funcionais.

\section{Resultados e Discussão}

Como já visto, o corpo é o lugar da experiencia subjetiva, a subjetividade por meio do corpo comparecerá a produção do trabalho, elaborando experiencias e soluções frente ao real (Dejours, 2012). O encontro com a realidade entrega ao corpo o peso do trabalho, carga que se distribui no cotidiano por meio de uma variedade de exigências: metas, posturas, horários, ritmo de produção, o entregar-se para atingir os objetivos na atividade assumida.

É nesta carga inerente a prática do trabalho que o trabalhador encontrará suas experiencias de sofrimento a priori para que então mobiliza-se a buscar soluções e prazer no trabalho. Focando no primeiro momento deste processo, o sofrer, foi possível perceber na análise das publicações selecionadas a recorrência do sentimento de sobrecarga. Moraes (2008) cita a sobrecarga como a principal fonte de sofrimento. Vieira (2011), Louzada (2014) e Calazans (2020) também pontuam o excesso de carga de trabalho como grande motivo de insatisfação e/ou ponto de sofrimento. Brito (2020) associa a sobrecarga diretamente a quadro patológicos no trabalho que é referido como desgastante. Mendes (2011) também cita uma sobrecarga sobre os trabalhadores e atrela esta ao acumulo de funções. Já Abreu (2013) e Mèlou (2018) não citam o termo propriamente dito, mas apontam o desgaste e cansaço em razão das jornadas de trabalho.

O tempo dedicado ao trabalho une o trabalhador ao seu ofício de forma integral, o desempenho de uma atividade é marcado no corpo do indivíduo, seja pelo fato do corpo ser o local de inscrição de uma identidade subjetiva, ou pela ação do ambiente físico ao qual este corpo está exposto em alta frequência. Essa conexão íntima entre corpo, subjetividade e trabalho pode ser notada de forma explicita na pesquisa de Louzada (2014), em que os profissionais legistas tinham entranhado em si o cheiro do corpo morto após o turno de trabalho ou observando de uma perspectiva mais simbólica carregam em si a ideia de contaminação na visão dos colegas de repartição, que optavam por manter certo distanciamento. Do mesmo modo está impressão do trabalho no corpo é notada na pesquisa de Brito (2020) onde há rígido controle até mesmo dos mínimos gestos corporais durante o exercício profissional. Ainda sobre essa questão a pesquisa de Calazans (2020, p.102) aponta como as exigências de trabalham modulam a postura corporal dos trabalhadores, a ponto que as exigências cotidianas fazem com que estes assumam postura corporal tensa e gestos bruscos.

Atentando para esta realidade em que o trabalho é imprimido no corpo, é imprescindível expor os riscos aos quais os trabalhadores estão expostos, tendo em vista que as consequências desses riscos deixarão marcas físicas e psíquicas nos trabalhadores. As pesquisas analisadas trazem à tona riscos físicos, químicos, biológicos e ergonômicos. Vieira (2011), Abreu (2013), Louzada (2014) Alvarenga (2018) pontuam a exposição a agentes biológicos que os trabalhadores estão expostos, risco recorrente aos profissionais da área da saúde, categoria que fazem partes nos profissionais entrevistados nestas pesquisas. Em Abreu (2013) e Louzada (2014) houve relatos de contaminação e adoecimento e trabalhadores.

Riscos químicos foram encontrados nas pesquisas de Vieira (2011), Nogueira (2011), Louzada (2014) e Abreu (2013) e Brito (2020). Riscos físicos e ergonômicos foram encontrados na totalidade das pesquisas analisadas e como consequências 
desses foi recorrente a escrita dos autores a respeito de dores de musculares, dores de cabeça e em outros membros do corpo assim como problemas ortopédicos. No escrito de Brito et al (2017) e Brito (2020) há um risco exacerbado, tendo em vista que além da integridade corporal há uma ameaça a vida dos profissionais.

O uso de Equipamento de Proteção Individual (EPI) seria uma medida prevenção importante frente aos riscos de acidente e adoecimento, porém a realidade exibe um cenário trabalhista em que está proteção individual não é efetiva, Nogueira (2011), Louzada (2014) e Brito (2020) apontam que os trabalhadores apesar de ter acesso aos equipamentos de proteção não fazem o pleno uso destes, as pesquisas mostraram que as circunstancias de trabalho não são propicias ao uso correto, Nogueira (2011) e Louzada (2014) afirmaram que a alta temperatura do ambiente de trabalho é um fator de impedimento para o uso continuo de EPI. Louzada (2014) e Brito (2020) mencionam a necessidade de compartilhamento de EPI, material que como o próprio nome já esclarece deve ser de uso individual. Em Alvarenga (2018) e Calazans (2020) relataram o não oferecimento do material de proteção. Em Alvarenga (2018) o autor expõe que a falta de EPI para os agentes comunitários de saúde levou os trabalhadores a uma maior frequência de adoecimento e Calazans (2020) relata que os trabalhadores do Centro de Atenção Psicossocial (CAPS) precisaram adquirir o produto com o dinheiro "do próprio bolso".

Perante os diversos perigos no ambiente de trabalho, o adoecimento em diversos níveis torna-se inevitável. Conforme seus respectivos ambientes de pesquisa, todos os autores relataram situações de adoecimento ligadas direta ou indiretamente ao trabalho. Vieira (2011) e Abreu (2013) relatam adoecimentos osteomusculares como os de maior incidência em suas pesquisas, esses surgiram em virtude grande e constante esforço físico das profissionais de enfermagem. Brito (2020) aponta adoecimento em razão dos movimentos repetitivos e posturas inadequadas dos bombeiros. Alvarenga (2013) cita a tendinite como comum na profissão, o que demonstra uma normalização da doença, o que remete a expressão popularmente conhecida como "ossos do ofício" que traz a ideia de um aspecto nocivo ou dificultoso é inerente a certo trabalho, ofuscante a reflexão que geraria alternativas para prevenção ou resolução de um problema de saúde. Moraes (2008) e Mèlou (2018) apontam queixas de dores de cabeça e musculares fruto dos esforços realizados durante a jornada de trabalho. Alvarenga (2018) expõe o adoecimento constante dos Agentes Comunitários de Saúde em razão de exposições climáticas sem a utilização de EPI que não é oferecido aos profissionais. Nogueira (2011) expões diversos casos de adoecimento por acidentes no trabalho relacionados a baques, exposição a produtos químicos, intensidade e frequência de esforço fisíco.

Uma questão importante exibida nas pesquisas foi a do trabalho noturno, Moraes (2008), Nogueira (2011) e Abreu (2013) indicam que este traz prejuízos a saúde em diversos âmbitos corporais, além disso prejudicam a convivência familiar e os vínculos sociais dos trabalhadores. Brito (2020) também relata a nocividade da perda de sono dos trabalhadores bombeiros que enfrentam escalas que englobam o período noturno.

A chegada do adoecimento envolve os trabalhadores em uma angustia física e mental, Vieira (2011) relata que o medo de perder o emprego faz com que alguns trabalhadores escondam seu estado não saudável, Moraes (2008) encontrou relatos de trabalhadores que sentem-se constrangidos a trabalhar mesmo doentes, em Nogueira (2011) isto também é uma realidade, os trabalhadores sofrem ao ter que expor sua doença pois contam passar por discriminação dos colegas, do mesmo modo ocorre em Brito (2020) em que os trabalhadores ocultam queixas sobre o adoecimento em razão do medo de cair em descrédito no trabalho.

Apesar do afinco em esconder a doença, ocultar dores e sintomas não é uma tarefa que se pode prologar. Quando o corpo grita por um freio o trabalhador vai de encontro com seu sofrimento, que não se limita a situação de doença, para mais está estreitamente vinculado a perda da capacidade laboral. As dores e o adoecimento podem levar a perda ou distanciamento da prática trabalhista, esta perda é danosa a saúde psíquica do indivíduo, Vieira (2011) esclarece isto:

"Geralmente, quando uma situação de adoecimento acomete o sujeito este sofre devido à dor, ao fato de ter que deixar de fazer coisas de seu cotidiano a qual está habituado a fazer, às vezes tem que se isolar da sociedade (internado em 
hospital, por exemplo), "sofrimentos comuns" relacionados com o adoecer. Ao adoecer o trabalhador deixa de produzir, tem que se afastar do trabalho, perde sua "utilidade" enquanto força de trabalho." (Vieira, 2011)

A questão do sentimento de utilidade está ligada ao reconhecimento, portanto afastar-se do trabalho significa afastar-se dos benefícios psíquicos do reconhecimento, Nogueira (2011) pontua a respeito disto:

"o adoecimento do trabalhador, desqualifica-o e o coloca na condição de homem incapaz de produzir, impede o reconhecimento do seu trabalho, seja pela empresa, seja pelos colegas de trabalho e muitas das vezes pela família e amigos. Estar doente é estar impossibilitado de trabalhar e ver seu trabalho reconhecido.” (Nogueira, 2011)

A pesquisa de Abreu (2013) enfatiza isto ao demonstrar que afastar-se do ofício para os trabalhadores entrevistados era como perder a própria identidade.

Ser barrado da possiblidade do reconhecimento implica em uma ferida no registro de identidade do indivíduo, a perda da função resulta, por conseguinte, na perda de ideias e ideais que o sujeito tinha a respeito de si mesmo. Dessa maneira, o adoecimento físico passa acarretar também a dor psíquica, deixando evidente a importância de uma preservação integral do indivíduo para manutenção de sua saúde mental, sendo imprescindível a criação de mecanismos que protejam o trabalhador nos âmbitos físico/corporal e psíquico e, portanto, gere proteção socialmente.

\section{Considerações Finais}

O exercício de uma atividade implica em dedicação e esforço psíquico e físico, as vivencias de prazer e sofrimento trarão ao trabalhador e a trabalhadores suas consequências. A dor causada pelos aspectos relacionados ao sofrimento incidirá sobre o corpo e sobre a subjetividade do indivíduo de forma dinâmica.

O cenário encontrado na análise das pesquisas aponta para uma relação intrínseca entre a organização e condições de trabalho e o adoecimento dos trabalhadores. Os trabalhadores se mostram sobrecarregados, buscando acatar ao real do trabalhado com intuito de cumprir as prescrições de sua atividade de forma viável, nessa busca pela realização do trabalho o sujeito passa a se expor a riscos presentes no ambiente do trabalho.

A convivência com os perigos encontrados nas condições de trabalho culmina por levar os trabalhadores a acidentes e adoecimentos, o que causa o abalo da sua integridade física e psíquica. $\mathrm{O}$ sofrimento não perpassa apenas pelas intercorrências que envolvem o adoecimento ou dano corporal, mas está também atrelado a um abalo na rotina, a análise das pesquisas demonstrou que o sofrimento por adoecer tem relação também com o afastamento do exercício do trabalho ou com a perda da capacidade laboral, que causam uma ferida na identidade do trabalhador, que vê seu papel social abalado.

As perdas causadas pelo adoecimento e por acidentes trazem um prejuízo generalizado, para o fluxo de andamento de trabalho da empresa, para os pares do sujeito acometido por acidente ou adoecimento que tem seu cotidiano modificado com um trabalhador ou trabalhadora a menos no seu setor ou equipe, e por fim abalam o individuo com foi afetado por doença ou acidente, prejudicando sua saúde mental e física e gerando uma serie de intercorrências em sua vida. A produção de estudos que ponham em pauta a estruturação dos modelos organizacionais do trabalho na atual conjuntura do sistema capitalista é de suma importancia para chamar atenção aos defeitos e faltas presente na forma como as instituições organizam seu ambiente de trabalho, possibilidando ajustes que visem a saúde dos trabalhadores. Portanto, é primordial a atenção a saúde do trabalhador e da trabalhadora com integralidade, considerando que deparado com o trabalho está um corpo que carrega subjetividade. Dessa maneira, a produção científica deve ir para além de um olhar biomédico, buscando uma visão focada em uma perspectiva subjetiva e social, que considere que todo evento repercutido no ambiente de trabalho trará marcas a subjetividade do indivíduo. 


\section{Referências}

Abreu, M. H. M. (2013). Subjetividade, Trabalho e Saúde dos servidores do hospital universitário João de Barros Barreto: prazer e sofrimento na aposentadoria. Dissertação de mestrado, Universidade Federal do Pará, Belém, PA, Brasil.

Alvarenga, E. C. (2013). A coragem de ser músico de orquestra sinfônica: Uma análise baseada na psicodinâmica do trabalho. Dissertação de mestrado, Universidade Federal do Pará, Belém, PA, Brasil.

Alvarenga, E. C. (2018). A corda bamba do trabalhar das equipes de saúde da família de Belém. Tese de doutorado, Universidade Federal do Pará, Belém, PA, Brasil.

Brito, J. M. B. D., Oliveira, K. R. D. S. G. D., Oliveira, P. D. T. R., \& Pimentel, A. D. S. G. (2017). A clínica do trabalho e o desvelamento do traumático no trabalho bombeiro militar: fragmentos de um caso clínico. Revista do NUFEN, 9(1), 148-163.

Brito, J. M. B. (2020). “Até onde o corpo aguenta somos humanos, depois disso somos bombeiros”: Análise dos riscos psicossociais relacionados à organização e às condições de trabalho bombeiro militar. Tese de doutorado, Universidade Federal do Pará, Belém, PA, Brasil.

Bueno, M., \& Macêdo, K. B. (2012). A Clínica psicodinâmica do trabalho: de Dejours às pesquisas brasileiras. ECOS-Estudos Contemporâneos da Subjetividade, 2(2), 306-318.

Calazans, D. A. (2020). É preciso amar para trabalhar: saúde mental dos trabalhadores de um CAPS II no estado do Pará. Dissertação de mestrado, Universidade Federal do Pará, Belém, PA, Brasil.

Dejours, C. (1986). Le corps entre biologie et psychanalyse. Payot.

Dejours, C. (1993). Coopération et construction de l'identité en situation de travail. Futur antérieur, 16(2), 41-52.

Dejours, C., Dessors, D., \& Desriaux, F. (1993). Por um trabalho, fator de equilíbrio. Revista de Administração de empresas, 33, 98-104.

Dejours, C. (2004). Subjetividade, trabalho e ação. Production, 14, 27-34.

Dejours, C. (2004). Addendum: da psicopatologia à psicodinâmica do trabalho. Christophe Dejours: da psicopatologia à psicodinâmica do trabalho, 2, 49-106.

Dejours, C. (2012). Psicodinâmica do trabalho e teoria da sedução. Psicologia em Estudo, 17, 363-371.

Dezin, N. K., \& Lincoln, Y. S. (2006). O planejamento da pesquisa qualitativa: teorias e abordagens. Artmed.

Freud, S. (1908). Moral sexual civilizada e doença nervosa moderna.

Lancman, S. \& Uchida, S. (2003). Trabalho e subjetividade: o olhar da psicodinâmica do trabalho. Cadernos de Psicologia Social do Trabalho, 6, 79-90.

Louzada, R. S. M. L. (2014). “Eu tenho medo é dos vivos”: análise Psicodinâmica do Trabalho entre profissionais da Medicina Legal. Dissertação de mestrado, Universidade Federal do Pará, Belém, PA, Brasil.

McDougall, J. (1989). Theaters of the body: A psychoanalytic approach to psychosomatic illness. WW Norton \& Co.

Mèlou, A. C. (2018). “Eu acho graça pra não chorar”: Uma análise da psicodinâmica do trabalho de operadoras de caixa de supermercado. Dissertação de mestrado, Universidade Federal do Pará, Belém, PA, Brasil.

Mendes, A. M. (2007). Psicodinâmica Do Trabalho: Teoria, Método e Pesquisas. Casa do psicólogo.

Mendes, A. B. (2011). Saúde mental e trabalho na assistência social: vivências de sofrimento psíquico e estratégias de defesa dos(as) Servidores(as) Públicos(as) Municipais da FUNPAPA em Belém/PA. Dissertação de mestrado, Universidade Federal do Pará, Belém, PA, Brasil.

MoraeS, R. D. (2008). Prazer-Sofrimento e saúde no trabalho com automação: estudo com operadores em empresas japonesas no Pólo Industrial de Manaus. Tese de doutorado, Universidade Federal do Pará, Belém, PA, Brasil.

Monteiro, J. K., Moraes, R. D., Freitas, L. G., Guizoni, L. D. \& Facas, E. P. (2019). Trabalho que adoece: resistências teóricas e práticas. Editora Fi.

Nogueira, L. S. M. (2011). O sofrimento negado: trabalho, saúdeldoença, prazer e sofrimento dos trabalhadores do alumínio do pará - Brasil. Tese de doutorado, Universidade Federal do Pará, Belém, PA, Brasil.

Silva, C. F. (2015). Saúde, prazer e sofrimento psíquico: uma análise do trabalho dos técnicos de um Centro de Referência de Assistência Social no Pará. Dissertação de mestrado, Universidade Federal do Pará, Belém, PA, Brasil.

Vieira, J. R. (2011). Cuidar adoecendo: o que fazer quando não posso mais usar todo o meu potencial de cuidar?. Dissertação de mestrado, Universidade Federal do Pará, Belém, PA, Brasil.

UFPA (2021). Programa de Pós-Graduação em Psicologia [Web Page]. https://ppgp.propesp.ufpa.br/index.php/br/. 